\title{
Article \\ Applicability of Food Grade Modified Starches as a Carrier of Microelements
}

\author{
Hanna Śmigielska ${ }^{1}$, Wioletta Błaszczak ${ }^{2}$ and Grażyna Lewandowicz ${ }^{3, *}$ (D) \\ 1 Department of Natural Science and Quality Assurance, Poznań University of Economics and Business, \\ 10 Niepodległości Avenue, 61-875 Poznan, Poland; h.smigielska@ue.poznan.pl \\ 2 Institute of Animal Reproduction and Food Research, Polish Academy of Sciences in Olsztyn, \\ 10 Tuwima St., 10-748 Olsztyn, Poland; w.blaszczak@pan.olsztyn.pl \\ 3 Department of Biotechnology and Food Microbiology, Poznań University of Life Sciences, \\ 48 Wojska Polskiego St., 60-627 Poznan, Poland \\ * Correspondence: grazyna.lewandowicz@up.poznan.pl; Tel.: +48-61-8466005
}

check for updates

Citation: Śmigielska, H.; Błaszczak, W.; Lewandowicz, G. Applicability of Food Grade Modified Starches as a Carrier of Microelements. Processes 2022, 10, 235. https://doi.org/ $10.3390 /$ pr10020235

Academic Editors: Chi-Fai Chau and Yue Li

Received: 11 January 2022

Accepted: 23 January 2022

Published: 26 January 2022

Publisher's Note: MDPI stays neutral with regard to jurisdictional claims in published maps and institutional affiliations.

Copyright: (C) 2022 by the authors. Licensee MDPI, Basel, Switzerland. This article is an open access article distributed under the terms and conditions of the Creative Commons Attribution (CC BY) license (https:// creativecommons.org/licenses/by/ $4.0 /)$.

\begin{abstract}
Growth in the human population and intensive, large-scale farming results in a lowering in the quality of nutrition. An oversupply of food energy is often accompanied with a deficiency in micronutrients. To address this problem, the food industry provides products enriched with bioactive substances. The main challenge of this technology is the even distribution of micronutrients in the matrix of the fortified food. A possible solution to this challenge is to use stable and effective carriers. The aim of this work was to verify the applicability of native potato starch and modified starches (commonly used in the food industry) as carriers for microelements. Adsorptions were carried out in starch suspensions at a temperature below gelatinisation. The native potato starch and the modified starches (E 1404, E 1412, E 1420, and E 1422) were assessed for their effectiveness in adsorbing copper, iron, and zinc sulphates or gluconates. Pasting characteristics were analysed using a Brabender viscograph and light microscopy. Furthermore, texture profile analysis of starchbased desserts was carried out with the use of the tested carriers. Starch in both its native and modified forms was able to effectively adsorb copper, iron, and zinc ions. Adsorption was more efficient when using modified starches containing hydrophilic carboxyl groups. The effectiveness of adsorption with oxidised starches increased with an increase in the degree of substitution. Starches containing more hydrophobic acetyl groups were less effective as adsorbents of microelements. The cation adsorption efficiency decreased in the order copper $>$ iron $>$ zinc, and sulphates were better adsorbed than gluconates. Copper ions influenced the pasting characteristics of the oxidised starches, and these effects were dependent on the degree of substitution with carboxyl groups. As observed by light microscopy, the presence of copper ions changes the interaction between the starch macromolecules and water. However, the above-mentioned changes did not significantly affect the texture of traditional sweet desserts. Starch, particularly its oxidised derivatives containing hydrophilic oxidised groups, can be recommended as a carrier of microelements for food fortification. The use of modified starches containing relatively hydrophobic acetyl groups is not appropriate because they absorb microelements less efficiently than native starch.
\end{abstract}

Keywords: functional food; carrier; starch; adsorption; microelements; texture; light microscopy

\section{Introduction}

Modern consumers who perfectly understand the relationship between diet and health are increasingly often looking for foods that provide a health benefit beyond basic nutrition. As a consequence, the market for functional foods is growing rapidly, especially in developed countries. Products enriched with probiotic bacteria and prebiotic polysaccharides, in addition to vitamins and some minerals, are widely offered [1-3]. This does not, however, solve all the problems associated with the appropriate feeding of a growing human population. Intensive, large-scale farming results in crops with a reduced content 
of micronutrients [4]. Thus, widespread malnutrition is commonly observed, even within the population of obese people. Malnutrition does not only relate to a lack of food, but also to an imbalance at the cellular level between the demand for all nutrients and their intake. Thus, an oversupply of food energy can be also accompanied by a deficiency in micronutrients that are indispensable for the metabolic activity of the human body. Micronutrients directly or indirectly affect the activity of enzymes involved in antioxidant defence systems, and deficiencies in some of these can often develop spontaneously in adults following ordinary diets [5,6]. Essential minerals include iron, copper, zinc, iodine, selenium, and chromium. Iron is a vital element for almost all living organisms, and plays an important role in oxygen transport. It is found in many important redox enzymes responsible for cell respiration. Iron deficiency is the most common nutritional deficiency globally, and is associated with common iron deficiency anaemia. However, an overdose of iron can cause the generation of highly reactive free radicals that can damage nucleic acids, proteins, and other cellular components [5,6]. Iron metabolism is closely related to metabolism of copper, and its deficiency may cause anaemia due to the difficult transport of iron to the tissues synthesising haemoglobin; that is, to the bone marrow [7]. The physiological importance of copper in the body is mainly related to the activity of ceruloplasmin-a copper-containing enzyme involved in the activation of iron stores in the liver. Ceruloplasmin catalyses the re-oxidation of $\mathrm{Fe}^{2+}$ to $\mathrm{Fe}^{3+}$, the only form in which iron can be transported from the liver to the marrow. Lack of copper also reduces intestinal iron transport [8,9]. Zinc has a multidirectional involvement in the proper functioning of cells, takes part in transcription and regulation, is a component of antioxidant enzymes, and lowers the levels of proinflammatory cytokines and markers of oxidative stress. Its deficiency can lead to serious problems, such as growth retardation or dysfunction of the immune response $[5,6,10]$.

To overcome the problem of micronutrient deficiency, the enrichment of food products with micronutrients is now a common practice undertaken by the food industry [11]. The first implemented procedures for the prevention of micronutrient deficiency within the entire population were salt iodisation and fortification of staple foods with vitamin A, folate, or zinc. At the initial stage of the development of this technology, the uneven distribution of the micronutrients in the matrix of fortified foods was a common flaw. As a result, some portions of the end-product (final product) had no added substance, whereas others had an excessive dose. To date, this remains a challenge for fortification technology. The solution to this problem may be the use of an appropriate carrier. The substance applied as a carrier should be easily miscible with food ingredients and inert in terms of both nutrition and flavour. Starch, the main macronutrient, seems to be a good choice, as it is tasteless, odourless, and does not discolour the food matrix. This polysaccharide is not limited to only being applied as the main source of energy in food, but can be used in agents that affect food texture-thickeners, stabilisers, or emulsifiers. Starch is cheap and generally recognised as safe, even in chemically modified form. Studies on the possibility of microencapsulation of bioactive substances using starch or its derivatives have also been undertaken [12-15]. In our previous work, we proved that copper and iron ions adsorbed by starch are evenly distributed within starch granules, in the form of complexes of octahedral or square-quadratic coordination, while maintaining the original crystal structure of starch [16]. The aim of this work was characterisation of the functionality of fortified starch in the food matrix. Special attention was paid to copper ions and their effect on the properties and microstructure of starch pastes. The advantage of the application of modified starches over native starch was also verified.

\section{Materials and Methods}

Commercial native potato starch and the most popular commercial food-grade-modified starches were used in this study. There were: distarch phosphate (E 1412), acetylated starch (E 1420), acetylated distarch adipate (E 1422), and three preparations of oxidised starches having different degrees of substitution (E 1404). These were kindly provided by Polish starch companies. 
The carboxyl and acetyl group content of starch was determined according to Joint FAO/WHO Expert Committee on Food Additives (JECFA) recommendations [17]. Measurements were repeated five times for each sample.

Adipic group content was determined by liquid chromatography, according to the improved procedure recommended by JECFA with small modifications. An Agilent Technologies 1200 Infinity LC (Santa Clara, CA, USA), Aminex HPX-87H $300 \times 7.8 \mathrm{~mm}$ column from BIO-RAD (Hercules, CA, USA)was used. A mixture of $0.001 \mathrm{M} \mathrm{H}_{2} \mathrm{SO}_{4}$ and acrylonitrile in a ratio of $96: 4$ was used as an eluent at an isocratic flow rate of $0.6 \mathrm{~mL} / \mathrm{min}$. Samples were loaded into the column in the amount of $30 \mu \mathrm{L}$. Qualitative and quantitative identification were carried out using pimelic acid as an internal standard. Measurements were performed at $80^{\circ} \mathrm{C}$, in triplicate.

Phosphorus content was determined using the spectrophotometric molybdenum blue method adapted for multiple analysis, as described in detail by Le Thanh-Blicharz et al. [18] The samples were mineralised in a microwave digestion system (CEM Corporation, Matthews, $\mathrm{NC}$, United States) according to the conditions recommended by the manufacturer of the microwave oven. After cooling, digests were diluted to $50 \mathrm{~mL}$ with demineralised water and kept at $4{ }^{\circ} \mathrm{C}$ until spectroscopic determination. Three digests were prepared for each sample. Two determinations were performed for each digest of the sample.

Copper II sulphate (analytical grade, Fluka Chemie, Buchs, Switzerland), iron II sulphate (Chempur, Piekary Ślaskie, Poland), iron II gluconate (Pol-Aura, Poznań, Poland), zinc sulphate (Merck, Darmstadt, Germany), and zinc gluconate (Merck, Darmstadt, Germany) were used for the adsorption. The adsorptions of copper, iron, and zinc ions were carried out in a starch suspension at the temperature of $50^{\circ} \mathrm{C}$ for $1 \mathrm{~h}$. For this purpose, the appropriate amounts of the enrichment substances, in the form of a solution, were added to the starch slurries. After completion of the adsorption, the starch was filtered, rinsed with demineralised water, and dried.

Determination of copper, iron, and zinc contents in starches was performed employing Flame Atomic Absorption Spectroscopy (F-AAS) using a Varian SpectrAA 800 (Australia). Starch samples were wet mineralised with 65\% nitric acid in a CEM MDS-2000 microwave digestion oven (CEM Corporation, Matthews, NC, USA). Standard AAS solutions used for calibration were purchased from Fluka Chemie (Buchs, Switzerland). The adsorption efficiency was calculated as the ratio of the amount of copper absorbed by the starch sample to the amount of copper introduced into the adsorption solution and expressed in [\%].

The pasting characteristics of starch suspensions were determined with a Brabender viscograph (Duisburg, Germany). Standard measurement parameters were set as: measuring cartridge $0.07 \mathrm{Nm}$, heating and cooling rate of $1.5^{\circ} \mathrm{C} / \mathrm{min}$ (within the $25-92.5-25^{\circ} \mathrm{C}$ range), and holding period of $20 \mathrm{~min}$ at $92.5^{\circ} \mathrm{C}$.

Light microscopy studies undertaken using the smear method [19]. For this purpose, a drop of the sample heated at a given temperature was transferred onto a glass slide and smeared. After cooling, the smear was stained with Lugol's solution (standard procedure). The preparations were examined with an OLYMPUS BX60 (Olympus, Shinjuku, Japan) microscope.

The fruit-flavoured sweet desserts (kissel) were made by pouring a suspension containing $20 \mathrm{~g}(\mathrm{dm}$.) of native potato starch in $60 \mathrm{~mL}$ of water into a boiling solution of $12.5 \mathrm{~g}$ of sucrose in $190 \mathrm{~mL}$ of water. The mixtures were boiled for another minute while stirring vigorously, and $0.5 \mathrm{~g}$ of citric acid was added. The resulting pastes were left for $4 \mathrm{~h}$ at room temperature. Ready-to-eat products were analysed for their universal texture profile.

The milk puddings were prepared using milk with a fat content of $2 \%$ and oxidised starch of DS $=0.0014$. For this purpose, the suspension containing $8.8 \mathrm{~g}(\mathrm{dm}$.) of oxidised starch and $25 \mathrm{~mL}$ of cold milk was poured into $100 \mathrm{~mL}$ of boiling milk containing $10 \mathrm{~g}$ of sucrose. The pudding was cooked for $30 \mathrm{~s}$ from the moment the first bubbles appeared on the surface of the pudding mass. Then, the pudding mass was cooled for $4 \mathrm{~h}$ at room temperature. The ready-to-eat products were assessed for their universal texture profile.

The fruit-flavoured jellies were prepared by suspending $30 \mathrm{~g}$ of oxidised starch $\mathrm{DS}=0.0036$ in $250 \mathrm{~mL}$ of water containing $50 \mathrm{~g}$ of sucrose, under constant stirring, which 
was brought to boiling temperature and maintained for 3 min. Then, with constant stirring, the jelly was cooled to $50^{\circ} \mathrm{C}$ and $1 \mathrm{~g}$ of citric acid was added. Then, the mixtures were cooled for $2 \mathrm{~h}$ at room temperature. Ready-to-eat products were assessed for the universal texture profile.

Desserts enriched with micronutrients were prepared in such a way that one portion of dessert ( $250 \mathrm{~g}$ ) contained 50\% of the RDA for a given element, i.e., $1 \mathrm{mg} \mathrm{Cu}$ and $7.5 \mathrm{mg}$ $\mathrm{Fe}$, respectively.

The universal texture profile (TPA) of the desserts was determined with a TA-XT.2 Texture Analyser, Stable Micro Systems (Godalming, England). The standard "double bite test" was performed with an aluminium cylindrical probe (35 $\mathrm{mm}$ diameter) at a depth of $20 \mathrm{~mm}$ with a speed of $0.5 \mathrm{~mm} / \mathrm{s}$. Hardness [N], adhesiveness [N.s], cohesiveness, springiness and gumminess $[\mathrm{N}]$ were determined.

\section{Results and Discussion}

\subsection{Screening of Starches}

Starch is a versatile polysaccharide playing the role of both an energy carrier for living organisms and a texture-forming agent in food [12]. Despite the high biodiversity of its origin, native starch in the latter role has numerous limitations. Therefore, it is often used in a modified form [14,20]. Physically modified starches are often used in food production because they are "clean label". However, due to exploitation of the reactivity of the three hydroxyl groups present in each anhydroglucose unit, chemically modified starches ensure a better adjustment of the physicochemical properties of starch to specific applications. For food production, over one dozen modified starches are legally permitted. Most of these are food additives applied in accordance with the quantum satis rule, and some even have the status of a food ingredient. However, for various technological and economic reasons, only a few are commercially popular [21]. Oxidised starches, containing hydrophilic carboxylic groups, have an increased ability to form gels, and therefore are primarily used in the production of dry mixes for the preparation of sweet desserts [22,23]. Distarch phosphates, the simplest cross-linked starches, are especially popular in the meat industry due to their unique ability to prevent leakage via the thermal treatment of ham or sausages [24]. Acetylated starches and doubly modified acetylated distarch adipates, due to the presence of slightly hydrophobic acetyl groups, have higher surface activity than that of native starch [25]. Therefore, they are useful in the manufacture of food emulsions such as mayonnaises, sauces, or margarines, and particularly in reduced-fat variants of these products. These four types of the most popular modified starches were the subject of screening for their suitability as a carrier of minerals in food.

As presented in the Table 1, significant differences in the adsorption efficiency between the studied starches were observed. The native potato starch, similar to distarch phosphate, was able to adsorb $90 \%$ of copper ions contained in the solution. Starches modified by esterification i.e., acetylated starch and acetylated distarch adipate, revealed an adsorption capacity of about $60 \%$, which is significantly lower than in the case of native starch. In contrast, oxidised starch stood out among all of the analysed starches due to having the highest efficiency, of $100 \%$. These data indicate that the chemical nature of the substituents present in the starch macromolecules played a key role in the adsorption process. Moreover, our data pointed to the ionic nature of the binding of copper ions by starch. Therefore, phosphate groups, which are inherently present in native potato starch, cannot be omitted when discussing the efficiency of adsorption. Although the degree of substitution (DS $=0.008$ ) with phosphate groups, which corresponds to the determined phosphorus content (Table 1), is rather low, there are three hydrogens in H3PO4 acid, with dissociation constants of $\mathrm{pKa} 1=2.14$, $\mathrm{pKa} 2=7.20$, and $\mathrm{pKa} 3=12.37$, which indicates their relatively high ion-binding capacity. Considering the above, further studies were performed with oxidised starch preparations having different degrees of substitution. 
Table 1. Basic chemical characteristics of the adsorption process and the starches studied.

\begin{tabular}{ccccccc}
\hline $\begin{array}{c}\text { Starch } \\
\text { Preparation }\end{array}$ & $\begin{array}{c}\text { Carboxyl Groups } \\
\text { Content [\%] }\end{array}$ & $\begin{array}{c}\text { Acetyl Groups } \\
\text { Content [\%] }\end{array}$ & $\begin{array}{c}\text { Adipate Groups } \\
\text { Content [\%] }\end{array}$ & $\begin{array}{c}\text { Phosphorus } \\
\text { Content [\%] }\end{array}$ & $\begin{array}{c}\text { Copper Ions } \\
\text { Content } \text { [mg/g] }\end{array}$ \\
\hline Native & - & - & - & $0.075 \pm 0.002$ & $0.46 \pm 0.02$ \\
\hline E 1404 & $0.10 \pm 0.01$ & - & - & $0.068 \pm 0.001$ & $0.50 \pm 0.04$ \\
\hline E 1412 & - & - & - & $0.071 \pm 0.002$ & $0.45 \pm 0.04$ \\
\hline E 1420 & - & $1.5 \pm 0.3$ & - & $0.068 \pm 0.003$ & $0.33 \pm 0.02$ \\
\hline E 1422 & - & $1.2 \pm 0.2$ & $0.03 \pm 0.01$ & $0.067 \pm 0.002$ & $0.28 \pm 0.03$ \\
\hline
\end{tabular}

* Copper ions content in the adsorption solution was $0.5 \mathrm{mg}$ per $1 \mathrm{~g}$ of starch.

\subsection{Oxidised Starches}

Oxidised starches have been used as auxiliary substances in many branches of industry for over 150 years. In this regard, modified starches differ not only in their degree of substitution, but also in their molecular structure [26]. Initially, they were applied mainly in the paper and textile industries to improve the mechanical properties for the printability of paper web or woven fibres [27].

At present, the use of hypochlorite-modified starch as a food additive is predominant. This modification method permits different substitution degrees to be obtained, and thus enables starch preparations with various rheological and gelling properties. This provides the possibility of their application as a texture-forming agent in a wide range of food products. Nevertheless, their main application is in the production of jellies and puddings [23].

\subsubsection{Adsorption of Copper Ions}

The experiment performed with higher concentrations of cooper ions (Figure 1) proved that oxidised starches were efficient adsorbents of copper ions, and that the effectiveness of adsorption strongly depended on the degree of substitution with carboxyl groups. Starch of DS $=0.018$ was definitely the best adsorbent. It was able to adsorb almost all copper ions from the solution up, to a dose of $4 \mathrm{mg} / \mathrm{g}_{\text {starch }}$. The use of starch with a higher degree of substitution would probably increase the adsorption efficiency, but such a starch could not be considered a food additive because the limit in the degree of oxidation for food-grade oxidised starches is DS $=0.04[17,28]$. Starch with DS $=0.036$, containing five times fewer carboxyl groups, was characterised by significantly lower adsorption efficiency, which essentially decreased linearly with an increasing content of copper ions in the solution. Native starch and oxidised starch of the lowest degree of substitution, DS $=0.0014$, revealed similar adsorption profiles. Oxidised starches were characterised by a slightly higher efficiency with a lower content of copper ions in the solution. In the case of a higher content of copper ions, the reverse dependence was observed. These slight differences may be related to a small decrease in phosphorus content caused by the hydrolysis of monophosphate bonds naturally present in potato starch. This process has been observed in relation to the production of distarch phosphates and acetylated distarch phosphates [18].

\subsubsection{Pasting Phenomena}

Rheological analyses, including viscography and rheometry, are primary methods used for the examination of the functionality of starch [29-32]. As viscographs aptly reflect technological conditions of application of starch preparations, this method was used in our study. Data presented in Figure 2 can be compared only in part, as the presented curves were recorded at different concentrations. The application of these parameters for rheological analyses was necessary due to the reduction in viscosity of starch preparations caused by hypochlorite treatment. Nonetheless, the effects of both the degree of substitution and the presence of copper ions could be observed. The native potato starch revealed high type of pasting characteristics, with a rapid increase in viscosity within a narrow temperature range and the occurrence of a viscosity peak. The presence of copper ions 
in the starch environment significantly changed the shape of this curve, making it more medium type, with a progressive rise in viscosity over a wide temperature range and the lack of a viscosity peak. The most significant effect of the presence of copper ions was the decrease in the final viscosity. A slight oxidation of DS $=0.0014$ resulted in a change in the type of pasting characteristics from high to medium. The effect of the presence of copper ions was small, but in this case an increase in final viscosity was observed. The pasting characteristics of more oxidised starch of DS $=0.0036$ resembled those of native starch However, this phenomenon may be the effect of a higher concentration of the analysed suspension. The most obvious effect was the higher torque values for fortified starch over the entire measuring range. This indicated the effect of cross-linking of starch by divalent copper ions. The most spectacular effects were observed in the case of the highest oxidised starch of DS $=0.018$. Although the analysis for suspension was performed at a concentration of $20 \%$, unfortified starch revealed medium swelling characteristics. However, fortified starch revealed the typical high pasting curve. Moreover, significant differences in torque values over the whole measuring range were observed. These phenomena can also be explained by cross-linking of starch by copper ions. Summarising the above, it can be stated that, apart from the known effect of oxidation on the rheological properties of starch, a significant influence of the presence of copper ions was also observed. However, this latter effect seems to be different for starches with different contents of carboxyl groups. One can expect cross-linking of starch by copper ions in all cases, but changes were not unequivocal. This is related to the kosmotropic/chaotropic effect, which is dependent on the concentration of solutes $[33,34]$. In the simplest manner, the observed differences can be explained by different concentrations of $\mathrm{Cu}^{+2}$ ions, caused by both different abilities of the different starches to adsorb copper ions and different concentrations of the pastes. To verify this hypothesis, light microscopy (LM) studies were carried out and the results are shown in Figure 3.

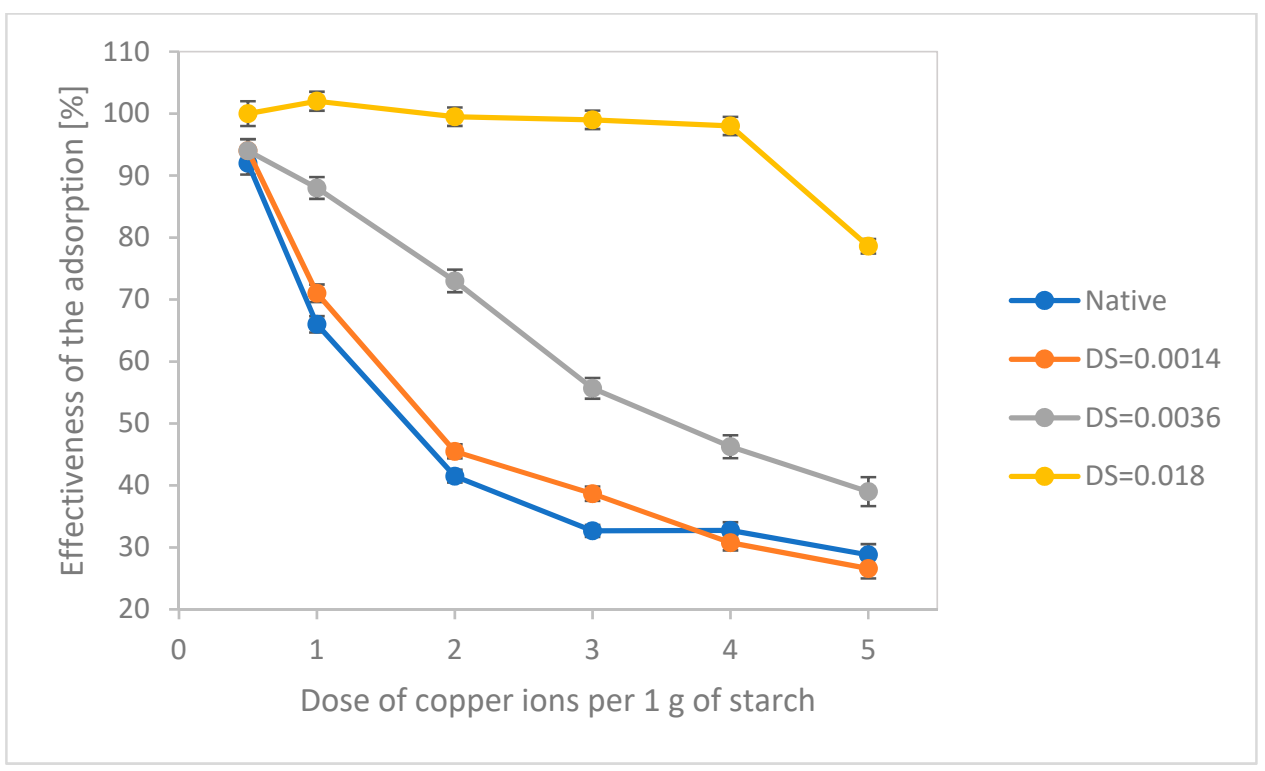

Figure 1. Effectiveness of the adsorption of copper ions by oxidised starches having different degrees of substitution $(n=3)$. 

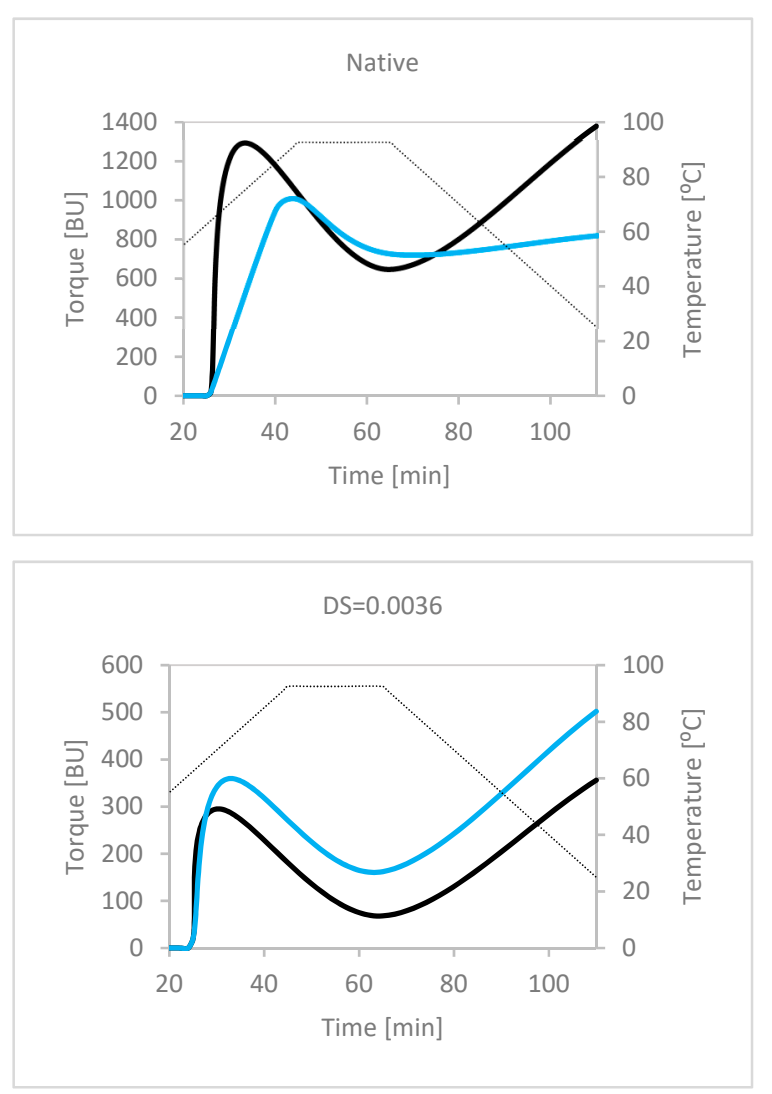
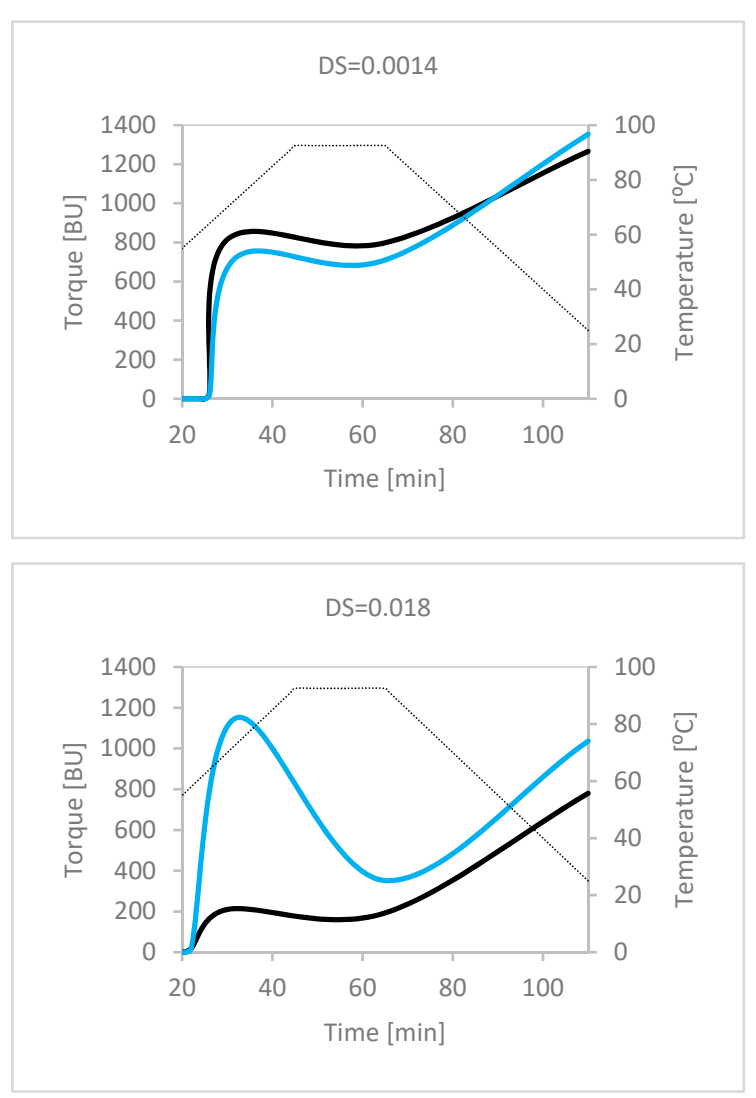

Figure 2. Pasting characteristics of plain (black lines) and fortified (blue lines) native and oxidised starches. Curves were recorded applying different concentrations of starch suspensions: native 5\%; DS $=0.0014-5 \%$; DS $=0.0036-8 \%$; and DS $=0.018-20 \%$.

Native
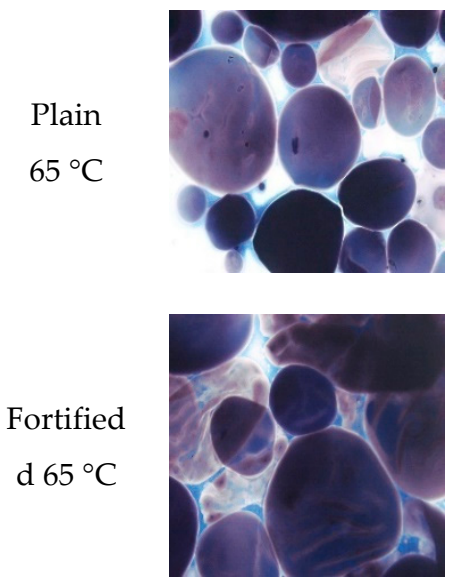

$\mathrm{DS}=0.0014$
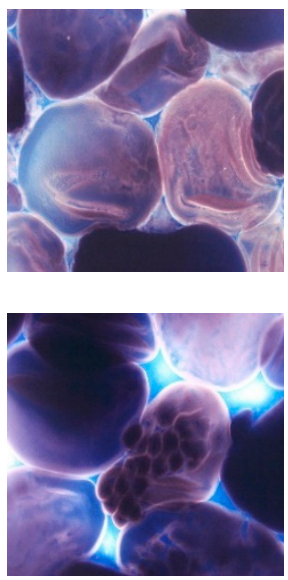

DS $=0.0036$
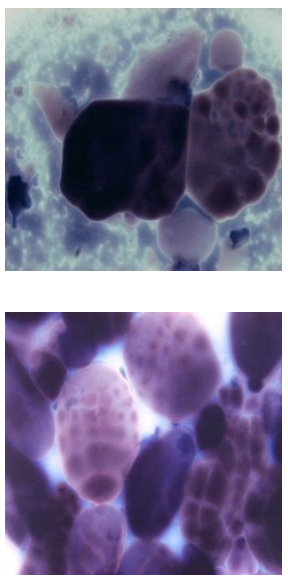

DS $=0.018$
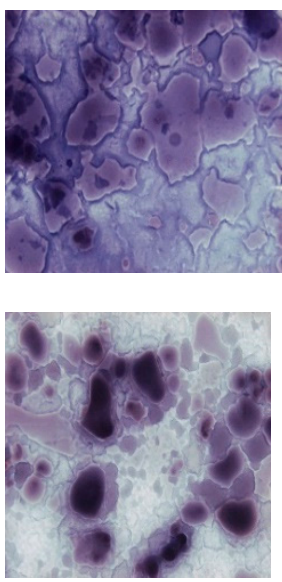

Figure 3. Cont. 


\section{Plain \\ $90{ }^{\circ} \mathrm{C}$}
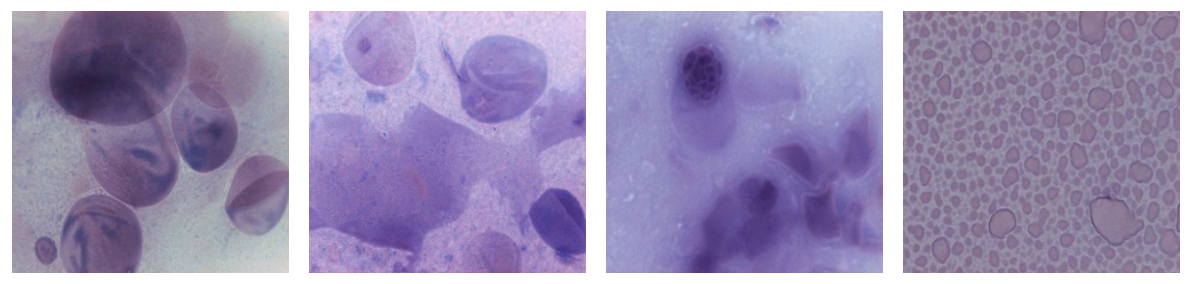

Fortified

$90{ }^{\circ} \mathrm{C}$
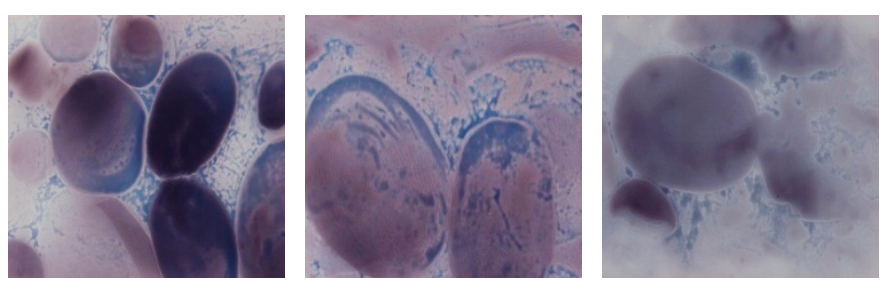

Figure 3. Light microscopy pictures of pastes of native starch and oxidised starches having different degrees of substitution, prepared at different temperatures. LM picture of pastes obtained from oxidised (plain) and fortified (oxidised, containing copper ions) starches with different substitution degrees heated at 65 and $90{ }^{\circ} \mathrm{C}$.

Light microscopy, which is a less-known starch analytical technique, is especially useful in studies of starch gelatinisation, the extent of molecular dispersion of its macromolecules in pastes, and the structural changes caused by modification. Due to the application of iodine staining, amylose (blue) can be easily distinguished from amylopectin (red) molecules. Moreover, the changes in the polymer-solvent interaction can also be successfully studied under LM [19]. In the images presented in Figure 3, it is possible to observe the effects of both the oxidation and the fortification with copper ions. The most pronounced effect of oxidation was the facilitation of the pasting process, which can be observed at the temperatures of 65 and $90{ }^{\circ} \mathrm{C}$. A microphotograph of native potato starch at $65{ }^{\circ} \mathrm{C}$ showed the very beginning stage of gelatinisation. Starch granules were swollen, but only a small amount of amylose leaked out. A picture of oxidised starch at DS $=0.0014$ at the same temperature corresponded to a more advanced gelatinisation process. Starch granules were more swollen and a large amount of amylose leaked out from them. By DS $=0.0036$, the typical gelatinisation process, which starts with the leakage of amylose, was accompanied by the disintegration of starch granules. Oxidised starch with the highest degree of substitution of DS $=0.018$ started gelatinisation mainly by the disintegration of the whole granules. At the temperature of $90{ }^{\circ} \mathrm{C}$, better dispersion of starch macromolecules for starches having a higher degree of substitution was also observed. When comparing microstructures of pastes of plain and fortified starches prepared at the temperature of $65^{\circ} \mathrm{C}$, primarily the agglomeration of starch macromolecules by copper ions could be seen. However, at the temperature of $90{ }^{\circ} \mathrm{C}$, the agglomeration of amylose molecules by copper ions was the primary effect only in the case of native starch. The major observation in the case of oxidised starches was the presence of more swollen granules and starch macromolecule agglomerates having larger dimensions. This explains the different effects of copper ions on the final viscosity of starches having different carboxyl group contents.

\subsubsection{Other Ions and Implementation of Ready to Eat Products}

The data presented above indicate the good efficiency of copper ion adsorption by oxidised starches, and suggest the possibility of adapting this procedure to enriching food with other substances. Furthermore, essential microelements are available in the form of different salts, most often sulphates, gluconates, and fumarates, which may be important both in terms of bioavailability and the adverse effects of these substances [35]. Moreover, as indicated from the obtained results, the ionic mechanism of interaction between starch and starch and salts may result in different degrees of effectiveness in the adsorption of 
these substances. To evaluate the susceptibility of various cations to the adsorption, in addition to the effect of the associated anion on this process, a preliminary study using zinc and ferrous sulphates and gluconates was carried out. The results are presented in Figure 4. The salts' concentration in the applied adsorption solutions corresponded to the content of $5 \mathrm{mg}$ of individual cations per $1 \mathrm{~g}$ of starch, i.e., the highest value applied in the study of the adsorption efficiency of copper sulphate. The experiment proved that iron ions were more efficiently adsorbed than zinc ions. Moreover, higher adsorption efficiency was observed with sulphates than with gluconates. Nevertheless, all the salts used in this stage of the study were adsorbed with less efficiency than copper sulphate. For this reason, adsorption of microelements in the form of sulphates should be recommended, particularly because they are present in the supplement market in this form [36].
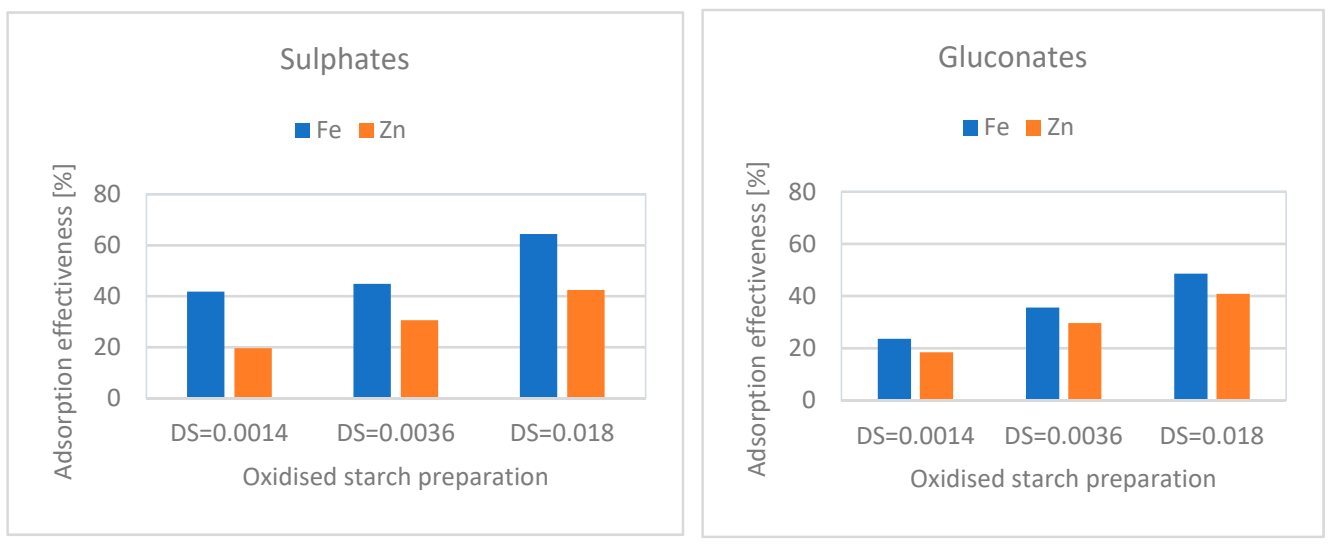

Figure 4. Effectiveness of the adsorption of iron and zinc sulphates and gluconates from the solutions containing $5 \mathrm{mg}$ of individual cations per $1 \mathrm{~g}$ of starch preparation.

In food technology, the importance of native potato starch and its derivatives obtained by hypochlorite treatment extends far beyond their role as a texture-forming agent. There is a long tradition of consumption of sweet, fruit-flavoured, and milk desserts based on starch in central and eastern Europe. They are often prepared at home using dry mixtures that are produced industrially. Mixtures for the preparation of fruit-flavoured desserts based on native potato starch, milk desserts based on oxidised starch having DS $=0.0014$, and fruit-flavoured jellies based on oxidised starch having DS $=0.0036$ are the most popular [23]. Comparison of the properties of ready-to-eat sweet desserts made with plain or fortified preparations makes it possible to clearly assess how enrichment affects food quality. Therefore, the texture of ready-to-eat desserts prepared using plain and fortified starches was studied. Desserts enriched with micronutrients were prepared in such a manner that one portion of dessert $(250 \mathrm{~g})$ contained $50 \%$ of the body's RDA for a given element, i.e., $1 \mathrm{mg} \mathrm{Cu}$ and $7.5 \mathrm{mg} \mathrm{Fe}$, respectively [37]. The results are presented in Table 2 . The presented data indicate that the texture parameters of individual types of desserts differed from each other. These differences are intentional and the result of the specificity of individual desserts. The differences within one type of dessert made from either plain starch or enriched starches were small and not relevant for consumer acceptance. These observations were confirmed by a consumer acceptance study (data not shown).

Table 2. Texture profile analyses of ready-to eat-desserts made with the starches studied.

\begin{tabular}{cccccc}
\hline Dessert & Hardness [N] & Adhesiveness [Ns] & Springiness & Cohesiveness & Gumminess [N] \\
\hline $\begin{array}{c}\text { Fruit flavour } \\
\text { sweet dessert plain }\end{array}$ & $4.37 \pm 0.58^{\mathrm{a}}$ & $4.61 \pm 1.11^{\mathrm{a}}$ & $0.98 \pm 0.05^{\mathrm{a}}$ & $0.80 \pm 0.14^{\mathrm{b}}$ & $3.46 \pm 0.60^{\mathrm{ab}}$ \\
\hline
\end{tabular}


Table 2. Cont.

\begin{tabular}{|c|c|c|c|c|c|}
\hline Dessert & Hardness [N] & Adhesiveness [Ns] & Springiness & Cohesiveness & Gumminess [N] \\
\hline $\begin{array}{l}\text { Fruit flavour sweet dessert } \\
\text { fortified with } \mathrm{Cu}\end{array}$ & $4.62 \pm 0.49^{a}$ & $6.14 \pm 5.25^{\mathrm{a}}$ & $0.96 \pm 0.04^{\mathrm{a}}$ & $0.63 \pm 0.06^{\mathrm{ab}}$ & $2.82 \pm 0.15^{\mathrm{ab}}$ \\
\hline $\begin{array}{l}\text { Fruit flavour sweet dessert } \\
\text { fortified with Fe }\end{array}$ & $3.91 \pm 0.22^{a}$ & $5.48 \pm 2.17^{\mathrm{a}}$ & $1.00 \pm 0.07^{\mathrm{a}}$ & $0.71 \pm 0.15^{\mathrm{ab}}$ & $2.78 \pm 0.722^{a b}$ \\
\hline $\begin{array}{l}\text { Milk sweet } \\
\text { dessert plain }\end{array}$ & $3.70 \pm 0.80^{a}$ & $16.75 \pm 8.67^{a}$ & $1.05 \pm 0.07^{\mathrm{a}}$ & $0.57 \pm 0.07^{\mathrm{ab}}$ & $2.10 \pm 0.46^{\mathrm{a}}$ \\
\hline $\begin{array}{c}\text { Milk sweet } \\
\text { dessert fortified with } \mathrm{Cu}\end{array}$ & $3.78 \pm 0.47^{\mathrm{a}}$ & $7.42 \pm 4.17^{\mathrm{a}}$ & $1.01 \pm 0.14^{\mathrm{a}}$ & $0.66 \pm 0.13^{a b}$ & $2.51 \pm 0.72 \mathrm{ab}$ \\
\hline $\begin{array}{c}\text { Milk sweet } \\
\text { dessert fortified with Fe }\end{array}$ & $3.26 \pm 0.52^{a}$ & $16.5 \pm 13.7^{a}$ & $1.02 \pm 0.02^{\mathrm{a}}$ & $0.66 \pm 0.09 \mathrm{ab}$ & $2.10 \pm 0.57^{a}$ \\
\hline $\begin{array}{l}\text { Fruit flavour } \\
\text { jelly plain }\end{array}$ & $7.52 \pm 0.16^{b}$ & $10.55 \pm 6.70^{a}$ & $0.99 \pm 0.07^{\mathrm{a}}$ & $0.49 \pm 0.03^{a}$ & $3.43 \pm 0.66^{\mathrm{ab}}$ \\
\hline $\begin{array}{c}\text { Fruit flavour } \\
\text { jelly fortified with } \mathrm{Cu}\end{array}$ & $6.27 \pm 0.71^{b}$ & $10.82 \pm 3.18^{a}$ & $1.03 \pm 0.02^{\mathrm{a}}$ & $0.61 \pm 0.07^{\mathrm{ab}}$ & $3.78 \pm 0.43^{b}$ \\
\hline $\begin{array}{l}\text { Fruit flavour } \\
\text { jelly fortified with } \mathrm{Fe}\end{array}$ & $6.57 \pm 0.92^{b}$ & $9.79 \pm 2.33^{a}$ & $1.02 \pm 0.03^{a}$ & $0.57 \pm 0.03^{a b}$ & $3.74 \pm 0.55^{b}$ \\
\hline
\end{tabular}

Copper ion content in the adsorption solution was $0.5 \mathrm{mg}$ per $1 \mathrm{~g}$ of starch. Mean values with the same letters $\left({ }^{\mathrm{a}},{ }^{\mathrm{b}}\right)$ in the columns are not significantly different $p>0.05$. The studies presented above proved that fortified starches can be successfully used in food production to increase its nutritional value without influencing sensory properties.

\section{Conclusions}

In both its native and modified form, starch is able to effectively adsorb copper, iron, and zinc ions. Adsorption is more efficient when using modified starches containing hydrophilic carboxyl groups. The effectiveness of adsorption with oxidised starches increases with an increase in the degree of substitution. Starches containing more hydrophobic acetyl groups are less effective as adsorbents of microelements. The cation adsorption efficiency decreases in the order copper > iron > zinc, and sulphates are better adsorbed than gluconates. Copper ions influence the pasting characteristics of oxidised starches, and these effects depend on the degree of substitution with carboxyl groups. As observed using light microscopy, the presence of copper ions changes the interaction between starch macromolecules and water. However, the above changes do not significantly affect the texture of traditional sweet desserts. Therefore starch, especially as an oxidised derivative, can be recommended as a microelement carrier for food fortification.

Author Contributions: Conceptualisation, H.Ś. and G.L.; chemical and rheological characterisation of starches, H.Ś.; adsorption experiment, light microscopy experiment. W.B.; H.Ś.; texture analyses, H.Ś.; writing—original draft preparation, G.L.; writing—review and editing, W.B. All authors have read and agreed to the published version of the manuscript.

Funding: This work was partly supported by the Department of Natural Science and Quality Assurance, Institute of Quality Science in Poznań University of Economics and Business, within the statutory research No. 511022371. The microelement adsorption and its content were studied at the Department of Natural Science and Quality Assurance in Poznan University of Economics and Business. The work was partly supported by the Institute of Animal Reproduction and Food Research, Polish Academy of Sciences in Olsztyn, Poland, within the statutory research. The microscopic study was conducted at the Department of Chemical and Physical Properties of Food, Institute of Animal Reproduction and Food Research, Polish Academy of Sciences in Olsztyn, Poland. Th work was partly supported by the Poznań University of Life Sciences within the project No. 506.771.030.

Institutional Review Board Statement: Not applicable.

Informed Consent Statement: Not applicable.

Data Availability Statement: Not applicable. 
Acknowledgments: The authors thank Agnieszka Drożdzyńska for the analyses of adipate group content, and Potato Processing Company Ltd. and WPPZ S.A. for the gift of starch samples.

Conflicts of Interest: The authors declare no conflict of interest.

\section{References}

1. Bakshi, A.; Chhabra, S.; Kaur, R. Consumers Attitudes Toward Functional Foods: A Review. Curr. Top. Nutraceutical Res. 2020, 18, 343-347. [CrossRef]

2. Sarkar, S. Potentiality of probiotic yoghurt as a functional food-A review. Nutr. Food Sci. 2019, 49, 182-202. [CrossRef]

3. Gupta, E.; Mishra, P. Functional Food with Some Health Benefits, So Called Superfood: A Review. Curr. Nutr. Food Sci. 2021, 17, 144-166. [CrossRef]

4. Welch, R.M.; Graham, R.D. Breeding for micronutrients in staple food crops from a human nutrition perspective. J. Exp. Bot. 2004, 55, 353-364. [CrossRef]

5. Kaźmierczak-Barańska, J.; Boguszewska, K.; Karwowski, B.T. Nutrition Can Help DNA Repair in the Case of Aging. Nutrients 2020, 12, 3364. [CrossRef] [PubMed]

6. Misner, B. Food Alone May Not Provide Sufficient Micronutrients for Preventing Deficiency. J. Int. Soc. Sports Nutr. $2006,3,51$. [CrossRef] [PubMed]

7. Brzozowska, A. Interactions between iron, zinc and copper and their consequences for nutritional practice. Pol. J. Food Nutr. Sci. 1998, 7, 603-616.

8. Meyer, L.A.; Durley, A.P.; Prohaska, J.R.; Harris, Z.L. Copper Transport and Metabolism Are Normal in Aceruloplasminemic Mice. J. Biol. Chem. 2001, 276, 36857-36861. [CrossRef]

9. Zerounian, N.R.; Linder, M.C. Effects of copper and ceruloplasmin on iron transport in the Caco 2 cell intestinal model. J. Nutr. Biochem. 2002, 13, 138-148. [CrossRef]

10. Cassandri, M.; Smirnov, A.; Novelli, F.; Pitolli, C.; Agostini, M.; Malewicz, M.; Melino, G.; Raschellà, G. Zinc-finger proteins in health and disease. Cell Death Discov. 2017, 3, 17071. [CrossRef]

11. Berner, L.A.; Keast, D.R.; Bailey, R.L.; Dwyer, J.T. Fortified Foods Are Major Contributors to Nutrient Intakes in Diets of US Children and Adolescents. J. Acad. Nutr. Diet. 2014, 114, 1009-1022.e8. [CrossRef] [PubMed]

12. Waterschoot, J.; Gomand, S.V.; Fierens, E.; Delcour, J.A. Production, structure, physicochemical and functional properties of maize, cassava, wheat, potato and rice starches. Starch-Stärke 2015, 67, 14-29. [CrossRef]

13. Dupuis, J.H.; Liu, Q. Potato Starch: A Review of Physicochemical, Functional and Nutritional Properties. Am. J. Potato Res. 2019, 96, 127-138. [CrossRef]

14. Ashogbon, A.O.; Akintayo, E.T. Recent trend in the physical and chemical modification of starches from different botanical sources: A review. Starch-Stärke 2014, 66, 41-57. [CrossRef]

15. Singh, J.; Kaur, L.; McCarthy, O.J. Factors influencing the physico-chemical, morphological, thermal and rheological properties of some chemically modified starches for food applications-A review. Food Hydrocoll. 2007, 21, 1-22. [CrossRef]

16. Śmigielska, H.; Lewandowicz, G.; Goslar, J.; Hoffmann, S. Binding of the Trace Elements: Cu(II) and Fe(III) to the Native and Modified Nutritive Potato Starches Studied by Electron Paramagnetic Resonance. Acta Phys. Pol. Ser. A 2005, 108, 303-310. [CrossRef]

17. FAO. Modified starches. Compendium of Food Additive Specifications. FAO JECFA Monogr. 2014, 16, 7-8.

18. Le Thanh-Blicharz, J.; Małyszek, Z.; Rybicka, I.; Lewandowicz, G. Cross-linking of potato starch with sodium trimethaphosphate is accompanied by hydrolysis of starch monophosphate ester bonds. In Proceedings of the 16th International Conference on Polysaccharides-Glycoscience, Prague, Czech Republic, 4-6 November 2020; Řápkova, R., Bužková, M., Čopíková, J., Šárka, E., Eds.; Czech Chemical Society: Prague, Czech Republic, 2020; pp. 69-71.

19. Błaszczak, W.; Lewandowicz, G. Light Microscopy as a Tool to Evaluate the Functionality of Starch in Food. Foods 2020, 9 , 670. [CrossRef]

20. Zia-ud-Din; Xiong, H.; Fei, P. Physical and chemical modification of starches: A review. Crit. Rev. Food Sci. Nutr. 2017, 57, 2691-2705. [CrossRef]

21. Walkowski, A.; Mączyński, M.; Lewandowicz, G. Tendencies in a development of food starch products market in Poland. In Starch: From Starch Containing Sources to Isolation of Starches and Their Applications; Nova Science Publishers, Inc.: New York, NY, USA, 2004; pp. 29-38.

22. Hall, F.G.; Jones, O.G.; O'Haire, M.E.; Liceaga, A.M. Functional properties of tropical banded cricket (Gryllodes sigillatus) protein hydrolysates. Food Chem. 2017, 224, 414-422. [CrossRef]

23. Sadowska, J.; Wronkowska, M.; Lewandowicz, G.; Soral-Śmietana, M. Rheological characteristics of oxidised potato starch. Pol. J. Food Nutr. Sci. 2006, 56, 311-318.

24. Lewandowicz, G.; Walkowski, A.; Błaszczak, W. Degree of Substitution of Crosslinked Starches vs. Functionality in Food Products. In Starch: From Starch Containing Sources to Isolation of Starches and Their Applications; Nova Science Publishers, Inc.: New York, NY, USA, 2004; pp. 75-95.

25. Prochaska, K.; Kędziora, P.; Le Thanh, J.; Lewandowicz, G. Surface activity of commercial food grade modified starches. Colloids Surf. B Biointerfaces 2007, 60, 187-194. [CrossRef] [PubMed] 
26. Wang, Y.-J.; Wang, L. Physicochemical properties of common and waxy corn starches oxidized by different levels of sodium hypochlorite. Carbohydr. Polym. 2003, 52, 207-217. [CrossRef]

27. Vanier, N.L.; El Halal, S.L.M.; Dias, A.R.G.; da Rosa Zavareze, E. Molecular structure, functionality and applications of oxidized starches: A review. Food Chem. 2017, 221, 1546-1559. [CrossRef]

28. Mortensen, A.; Aguilar, F.; Crebelli, R.; Di Domenico, A.; Dusemund, B.; Frutos, M.J.; Galtier, P.; Gott, D.; Gundert-Remy, U.; Lambré, C.; et al. Re-evaluation of oxidised starch (E 1404), monostarch phosphate (E 1410), distarch phosphate (E 1412), phosphated distarch phosphate (E 1413), acetylated distarch phosphate (E 1414), acetylated starch (E 1420), acetylated distarch adipate (E 1422), hydrox. EFSA J. 2017, 15, e04911. [CrossRef]

29. Ai, Y.; Jane, J. Gelatinization and rheological properties of starch. Starch-Stärke 2015, 67, 213-224. [CrossRef]

30. Le Thanh-Blicharz, J.; Lewandowicz, J. Functionality of Native Starches in Food Systems: Cluster Analysis Grouping of Rheological Properties in Different Product Matrices. Foods 2020, 9, 1073. [CrossRef]

31. Gałkowska, D.; Długosz, M.; Juszczak, L. Effect of high methoxy pectin and sucrose on pasting, rheological, and textural properties of modified starch systems. Starch-Stärke 2013, 65, 499-508. [CrossRef]

32. Varela, M.S.; Navarro, A.S.; Yamul, D.K. Effect of hydrocolloids on the properties of wheat/potato starch mixtures. Starch-Stärke 2016, 68, 753-761. [CrossRef]

33. Cray, J.A.; Russell, J.T.; Timson, D.J.; Singhal, R.S.; Hallsworth, J.E. A universal measure of chaotropicity and kosmotropicity. Environ. Microbiol. 2013, 15, 287-296. [CrossRef]

34. Zhang, Y.; Cremer, P. Interactions between macromolecules and ions: The Hofmeister series. Curr. Opin. Chem. Biol. 2006, 10, 658-663. [CrossRef] [PubMed]

35. Joosten, E. Iron deficiency anemia in older adults: A review. Geriatr. Gerontol. Int. 2018, 18, 373-379. [CrossRef] [PubMed]

36. Cancelo-Hidalgo, M.J.; Castelo-Branco, C.; Palacios, S.; Haya-Palazuelos, J.; Ciria-Recasens, M.; Manasanch, J.; Pérez-Edo, L. Tolerability of different oral iron supplements: A systematic review. Curr. Med. Res. Opin. 2013, 29, 291-303. [CrossRef] [PubMed]

37. Recommended Dietary Allowances, 10th ed.; National Research Council-National Academy Press: Washington, DC, USA, 1989; Volume 24, pp. 32-33. [CrossRef] 